This article was downloaded by: [University of Sydney]

On: 03 May 2015, At: 09: 39

Publisher: Routledge

Informa Ltd Registered in England and Wales Registered Number: 1072954

Registered office: Mortimer House, 37-41 Mortimer Street, London W1T

3J H, UK

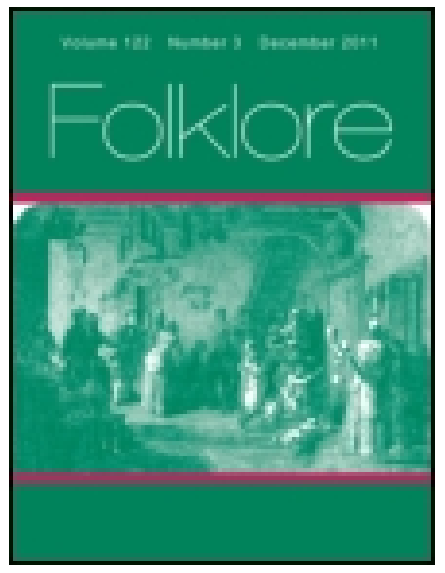

\title{
Folklore
}

Publication details, including instructions for authors and subscription information:

http:// www. tandfonline.com/loi/ rfol20

\section{The Cimaruta: Its Structure and Development}

\author{
R. T. Günther M.A. F. L.S. ${ }^{a}$ \\ a Magdalen College, Oxford \\ Published online: 06 Feb 2012.
}

To cite this article: R. T. Günther M.A. F. L.S. (1905) The Cimaruta: Its Structure and Development, Folklore, 16:2, 132-161, DOI: 10.1080/ 0015587X.1905.9719445

To link to this article: http:// dx. doi.org/ 10.1080/0015587X.1905.9719445

\section{PLEASE SCROLL DOWN FOR ARTICLE}

Taylor \& Francis makes every effort to ensure the accuracy of all the information (the "Content") contained in the publications on our platform. However, Taylor \& Francis, our agents, and our licensors make no representations or warranties whatsoever as to the accuracy, completeness, or suitability for any purpose of the Content. Any opinions and views expressed in this publication are the opinions and views of the authors, and are not the views of or endorsed by Taylor \& Francis. The accuracy of the Content should not be relied upon and should be independently verified with primary sources of information. Taylor and Francis shall not be liable for any losses, actions, claims, proceedings, demands, costs, expenses, damages, and other liabilities whatsoever or howsoever caused arising directly or indirectly in connection with, in relation to or arising out of the use of the Content.

This article may be used for research, teaching, and private study purposes. Any substantial or systematic reproduction, redistribution, reselling, loan, sub-licensing, systematic supply, or distribution in any form to anyone is 
expressly forbidden. Terms $\&$ Conditions of access and use can be found at http://www.tandfonline.com/page/terms-and-conditions 


\title{
THE CIMARUTA: ITS STRUCTURE AND DEVELOPMENT.
}

\author{
R. T. GONTHER, M.A., F.I.8. \\ Magdalon College, Oxford. \\ (Read at Meating, 15th March, 1905.)
}

SUPERSTITIOUS observances, which have either been long extinct or are half smothered beneath a cloak of shame among Northern Europeans, still flourish with a surprising vigour in Southern Italy; nay, are so grafted upon the ordinary customs as to constitute a very real part of the everyday life of the people. Foremost among these superstitions, and perhaps the most deeply rooted of them all, is the belief in the power of the Evil Eye, the malocthio, or, to use a more entirely Neapolitan expression, the jettatura.

Jettatori, or bringers of ill-luck, differ from witches in the northern sense, in that ill-luck may be brought on by them unconsciously, and without malice prepense. This evil influence may at any moment cast a spell on the unwary. A chance meeting with the jettatore when you are on business bent, will mar the issue of it; if he kindly wishes you "good-day," your day will be a series of annoyances, if not of misfortunes; his presence anywhere will occasion accidents which will affect all present but himself. Even animals do not escape; but the most susceptible to the malign influence are the firm believers in it, the ignorant, and the very young.

In Naples, amulets intended to secure the wearer against the power of the jettatore, are to be procured at reasonable 
prices at the coral and tortoise-shell, silversmiths', and jewellers' shops, which are patronised by rich and poor alike. In their show-cases may be seen rows of twisted pieces of coral, hearts fashioned from bone, shell, and coral, fists with fingers variously extended or doubled up, hunchbacked mannikins, pigs, nuts, trefoil, claws, horns, teeth, and many others besides. For the modest sum of half a franc anybody may become the possessor of a talisman warranted to avert all the manifold ills that flesh is heir to; and even of up-to-date collections of such amulets, strung up together on a central ring so as to form complete batteries, which must be invincible in the struggle against all possible kinds of evil! But in the smaller shops, in quarters frequented by a more rustic clientele, and in the provinces, the amulets are of less modern type, and, though of inferior workmanship, bear a closer resemblance to those of older date, which are often to be picked up at the curiosity-dealers, and whose prototypes are to be found in museums.

It is the Neapolitan's firm conviction that an amulet of ancient type; well-wornind bearing the scars of many an encounter with the powers of evil, is none the less potent as a guardian against nefarious influences. It is a fact that those who believe most implicitly in evil powers are the nicest in their choice of amulets, and do not entrust their persons to any but charms of material, construction, and type, approved and known to have stood the test of ages, rather than to many of the much vaunted novelties which hang in the shop windows-such forsooth, are hardly powerful enough to protect a dandy's watch-chain!

To-day I wish merely to draw attention to a certain group of charms especially dedicated to the service of infants. Two of these, the Sea-horse or Cavallo Marino and the Sirena, are simple, and often carry pendant bells like the corals which protected our childhood; but the third type, the Cimaruta or Sprig of Rue, is a 
compound charm-of some complexity-built up of parts which all add to the virtue of the charm.

By a compound charm is here meant one that has arisen from the blending together of originally separate amulets. Every single element of the cimaruta is known to exist separately and to function as a charm with properties more or less distinct from those of the other.elements. Traces of such separate origin are still to be found in many cimarute, in which loops are attached to the individual elements. These loops are purposeless in the composite form, and can only be explained like the "rudimentary organs" or vestigial structures of living organisms, since they are derived from the functional loops of suspension of ancestral simple amulets.

Notwithstanding the varied proportions and positions of the component parts of the cimaruta, a certain uniformity of plan is always conspicuous, but in its modifications it is an excellent instance of the laws of evolution. The result of repeated copying has been that certain portions of some charms have undergone a gradual process of reduction, and this no doubt would have continued until the whole design had become absolutely conventional were it not for the fact that the efficacy of the charm would be impaired by too great a departure from the prototype. The requirements of technique and of decorative art have also played a part in the production of series of interesting variations. Rarely are private marks and badges introduced.

Typical cimarute measure about three inches long by two inches broad. At the present day they are invariably made of silver, but in ancient times other metals seem to have been employed, for the Etruscan amulet depicted by Mr. Elworthy (Evil Eye, Fig. 161) seems to have been a cimaruta, and is of bronze (PL.XI.). Nowadays the silver is so essential a part of the charm that the prudent purchaser will not take one unauthenticated by a hall-mark, and he 
will sometimes look for the zigzag scratchings of the assayer as well. The Neapolitan mark is usually impressed either upon the stem or upon the loop of the charm.

Specimens of Neapolitan Silver-marks of the Eighteenth Century.
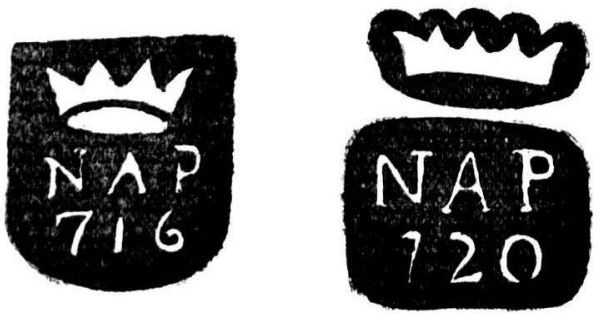

The wearer usually passes round his neck the light silver chain which is linked in the hole in the stem of the charm. The work may be executed in cast, carved, or hammered silver, but very inferior stamped specimens of modern manufacture are common, many being especially made for antiquity-hunters.

The branching framework of the charm is said to be a representation of the "sprig of rue," implied in the name cima di ruta. Upon the branches of this sprig are placed other emblems, as are the ornaments on a Christmas tree.

In a cimaruta of good workmanship we can recognise the following emblems:-(I) Rue, (2) Hand, (3) Moon, (4) Key, (5) Flower, (6) Horn or Fish, (7) Cock or Eagle ; occasionally (8) Heart in especially elaborate specimens, probably of later date, when other emblems, such as (9) Serpent, (IO) Cornucopia, (I I) Cherub, may also occur.

These emblems are added to the rue, much as the symbolic figures which we find in many Gnostic gems and medals are grouped around an eye (cf. Jahn, Aberglauben des bösen Blicks), and have been picked out for the purpose of increasing the efficacy of the charm. 
I will now deal separately with the component elements of the cimaruta. And, first as to the sprig of rue.

\section{Rue.}

No one would connect these charms with the rue, were it not for their name, for they might represent most other branching structures with equal truth. However, on comparing some cimarute with rue-sprigs, with ripening fruits culled during the later months of the year, a certain analogy can be perceived. 1

The stems of the rue bear alternate, petiolate and very much divided leaves (Pls. X. and XI.). The yellow flowers are disposed in corymbs at the summit of the branches; the calyx is persistent, and divided into four or five segments ; the corolla consists of as many oval petals, and is longer than the calyx. The fruit-bearing sprays bear lanceolate bracts near the bases of the fruits. It would appear that the cimaruta was modelled rather from the fruiting spray than from any other part of the rue plant ; for although in some of the type shown in Plate XV., Fig. 19, there are many small processes which presumably represent the lanceolate bracts borne upon the fruiting sprays, the leaves do not ever seem to be represented.

The following features may be recognized as common to. both the fruiting spray of the rue and its imitation:

(1) There are three main terminal branches.

(2) The branching is alternate, and not opposite (like a trident).

(3) There are swellings at the ends of all the branches.

If we select for comparison the least conventional of the cimarute, we shall be struck by other points of resemblance to the natural prototype. The knobs at the ends of the

1 Tho species most frequently grown in our English gardens is Ruta sraweolows $L_{n}$, which is common in Greece and Italy, and was probably the Itravos of Dioscorides. $R$. montana and $R$. chalepensis are species of shrubby habit found in Greece. 
Plate $X$.

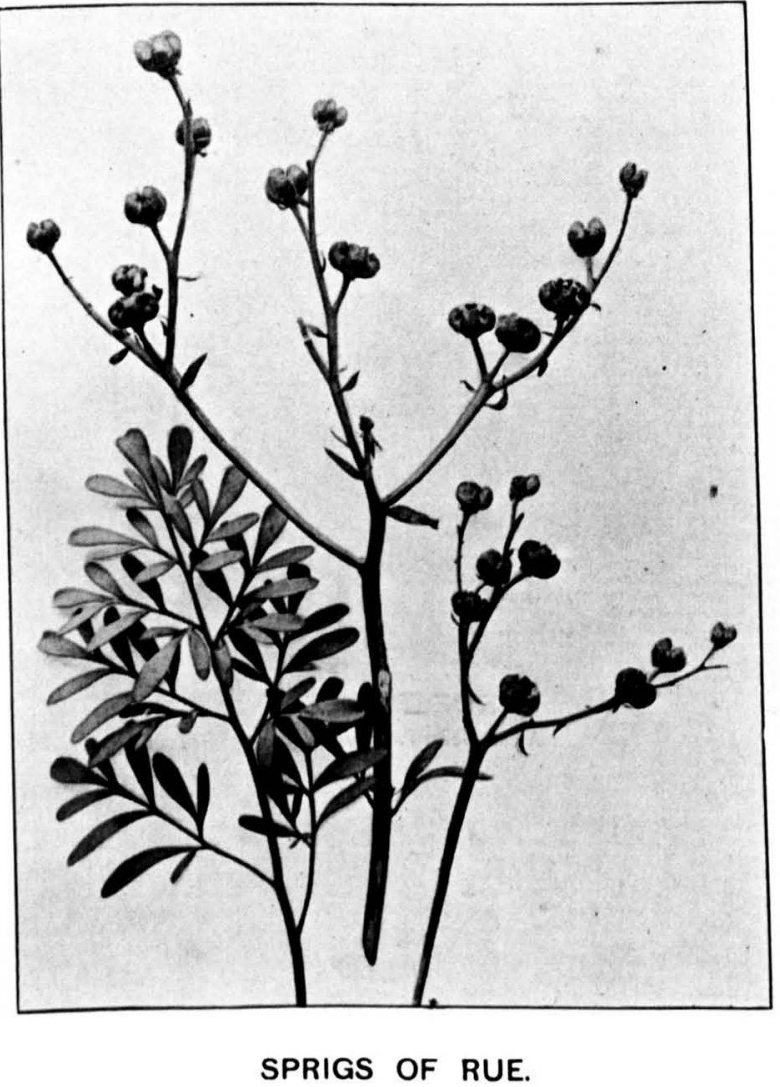

Photographed by Mr. A. H. Church from plants

grown in the Physick Garden at Oxford.

To face p. $13^{6}$. 
Plate XI.

$R$ Rutahorten/s. Garden Rue.
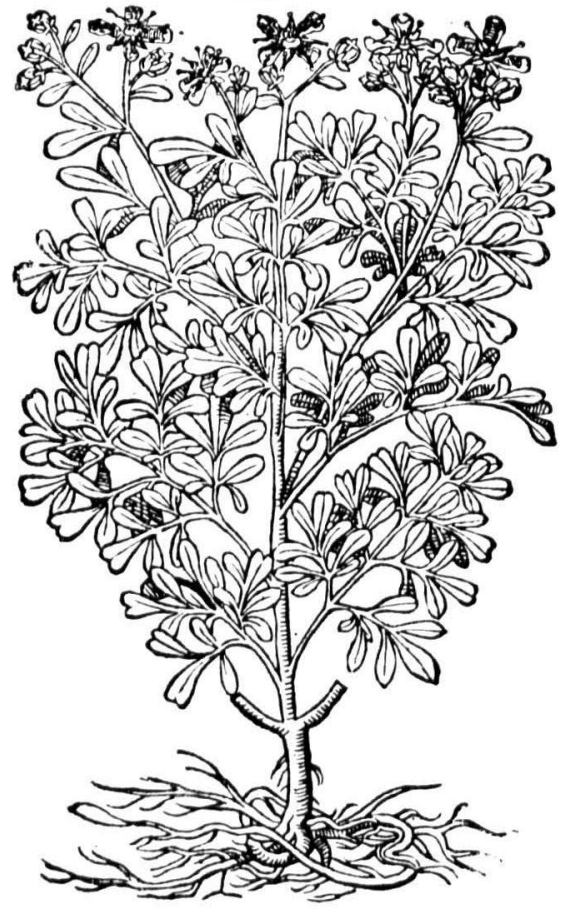

RUE PLANT.

After Gerard's Herbal, 1597 .

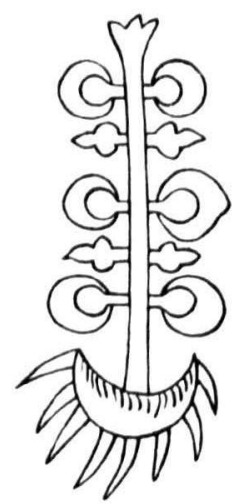

LUNARIA

After a $15^{\text {th }}$ Century drawing.

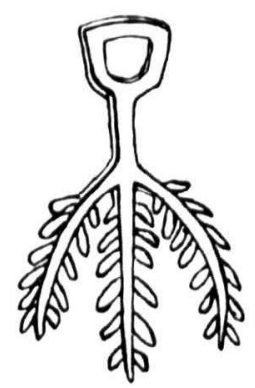

ASSYRIAN AMULET. After Lajard, Culte de Mithra.

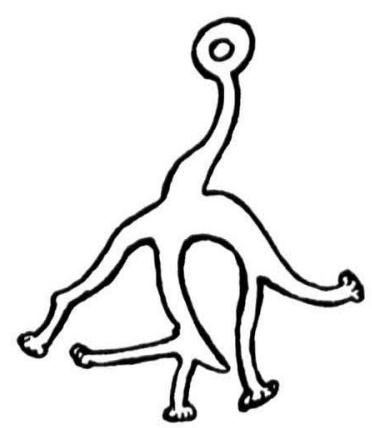

BOLOGNA AMULET.

After Elworthy, Fig. 161. 
branches of the charm will be seen to be divided into segments, in very fair imitation of flower-buds or seed-pods copied by unscientific craftsmen. In this connection a comparison with the old engravings of the herbalists will prove instructive (cf. Gerard, Herbal, p. 12, P1. XI.). On the whole, when we consider how easily a conventional design may depart from scientific truth when repeated by men who never saw the real thing in their lives, it is a matter for surprise rather than the reverse that there should be any trace at all of the rue-sprig in the conventional cimaruta.

Unmutilated silver cimarute representing the rue-sprig without extraneous emblems are rare at the present day; but a bronze amulet found at Bologna (Pl. XI.) is of this type, and, like the modern forms of the charm, the three main branches with twigs ending in small swellings are conspicuous.

Lest it should be thought that too much importance is attributed to the three-fold branching, which may be but an accidental arrangement, I must remind my readers that this branching has been considered by some to have a more recondite significance. Mr. Elworthy (Evil Eyer p. 348) observes that he "can come to no other conclusion than that the three branches are typical of Diana triformis or of her prototypes," but as the alternate character of the branching is true to nature, I hesitate to see the diva triformis in this triplicity.

We now pass to the consideration of the peculiar qualities of rue which have given rise to the use of silver images of it to counteract fascination.

Rue, or "herb of grace," has always had a widespread medicinal reputation. Eighty-four maladies were known to be treated by it in Pliny's day. Judges of Assizes no less than the contemporaries of Aristotle believed in its efficacy; a bunch of the herb sufficed to keep gaol-fever from the august bench; a tuft, worn as an amulet was thought to disarm the power of witchcraft. Even weasels, 
wrote Pliny, protected their pelt with rue before hazarding themselves in combat with the serpent. At the present day in Khorasan they burn an allied odoriferous herb (Peganum harmala) to purify the air.?

A very large proportion of the attributes of rue are shared by the class of plants which are associated with the Moon. The Botrychium lunaria (Moonwort), Artemisia (Southernwood and Mugwort), and Origanum dictamnus (or Cretan Dittany) are all supposed to repel serpents, thus possessing the property ascribed to the Moon in the Vedic books. The plants of the Moon have all to a greater or less degree acquired some share in the characteristics of the Moon-deity, who has been regarded as having all waters and moisture in the world under general control, and as more particularly exercising an influence on the diseases of the mind, on the dew of early morn which refreshes all vegetation, the sap of plants on which their growth and multiplication depends, on child-birth and the health of women. And so plants which either by experience or by the doctrine of signatures or otherwise are believed to be cures for ailments directly related to the sphere of influence of the moon, are regarded as intimately connected with the deities who were thought to personate that luminary. The Moon-Daisy and other composite flowers have become consecrated to the goddess Lucina, who presided over the birth of children; and there is little doubt but that the Rue, although a nostrum of-wider application, belonged to the same category; for in the fifth century B.C. it was described by Hippocrates as promoting the catamenia, and nearer our own time Boerhaave states that he employed it successfully in the treatment of several feminine complaints. It is therefore not surprising

\section{- 1 Aitchison, Nates on the Arodiucts of W. Afghasistan, p. 149.}

'Our illustration of Lumaria (P1. XI.) is from the I5th century Bodleian MS. Add. A. 23, f. 78.

In the 15th century botanical MS. in the Bodleian Library (MS, Selden 
to find that in an ancient floral vocabulary Rue should be entered as the floral sign or emblem of the "Fecundity of Fields" (Dierbach, Flora Mythologica der Griechen und Römer).

Very many other virtues have at various times been ascribed to Rue, but these in my opinion have for the most part nothing whatever to do with the cimaruta as at present used in Southern Italy. Amongst other properties is its utility in cases of madness and nightmare, and, according to the teaching of the Salerno School, it clears the sight as well as the perceptions of the mind. The association of the herb with the Sun and the constellation Leo, briefly alluded to by Culpeper ${ }^{2}$ (English Physitian Enlarged, 1656, p. 324), has an astrological significance probably foreign to those associations with the Moon which are our more immediate concern.

The silver Rue-sprig, then, as the basis of the cimaruta is potent as the more or less realistic representation of the part of the rue-plant or the material curative agent concerned with fertility and child-birth. It represents the influence of the lunar deity, and although but rarely found as a simple amulet, it forms the foundation of a compound charm in which its virtues are enhanced by the addition of the emblems to be next described.

It will be noticed that the majority of the conjoined

35), known as the Alphife, we read "Ruta menstrais imperat comesta et bibita Item rute cuios triplex est materies, a. domestice et silveatris, cuine semen piganum dicitur ; foliis et semine utimur." Compare also the earlier descriptions accompanying the excellent coloured illustration of me in Bodl. MS. 130 f. 27 (circ. A.D. 1100). This MS. was written in England, perhaps in the Abbey of Burg St. Edmond's, to which it belonged in the 14th centary.

'An explanation is given by W. Coles, the IIerbalist, in Adam and Fres, 1657, p. 45. He wrote: "I know not what religion Crollius was of i bat he with, that the rigne of the Crosse which is upan the seed, or mather, as I suppoes, the flower of Rno driveth away all Phantesms, and evill Spirite, by Signature"

"Gerard, too, affirms rue to be "bot and drie" (Herbal, 1597). 
emblems have properties similar to those of the rue, and in examples of degenerate cimarute the rue may dwindle and be almost entirely replaced by the added emblems.

\section{Hand.}

Although hands clenched in varied attitudes are often worn as simple amulets, yet the manofica, or fist clenched with the thumb doubled under and projecting between the knuckles of the index and second fingers, is the only form met with in combination with the cimaruta; and I believe it to have been one of the first amulets added to the rue.

Mr. Elworthy has collected many instances from different times and countries which show that as a charm against the evil eye this clenched fist is operative chiefly on account of its being regarded as one of the most insulting gestures it is possible to make. The manofica is usually affixed to the very extremity of the cimaruta, where its rude strength may receive the full brunt of the attack of evil and speedily avert it. Mr. Elworthy regards the knobs at the tip of every twig of the rue spray as indicating this powerful emblem, but it seems more likely that they are, as we have already pointed out, simply the buds or fruits of the rue.

Clenched fists are extensively used in combination with one or more of the other amulets. We find it combined with the moon, with the key (Pl. XIV., Fig. 4 i.), and with a flower (Fig. 2. iii.), and the latter combination is the one which is used in the peculiar bodkins the Sorrentine women wear in their hair (p. I44).

As a simple talisman, a hand with extended first and fourth fingers occurs both by itself and in combination with the flower or other emblem, but not with the sprig of rue. It may be taken to possess the same properties as a pair of horns or a two-horned crescent. 


\section{Moon.}

It is rare to find a cimaruta without the lunar emblem : it usually takes the form of a crescent, with a well-moulded face between the horns. The jettatura is baffled by the two-horned phase with greater certainty than by the more benign face of the full moon ; occasionally, however, representations of the full moon are included in the compound charm, and sometimes in addition to the crescent.

When the crescent is worn as a separate charm by human beings, a simple loop for suspension is fixed to the upper part and the charm is worn upright, with face looking forward ; 1 but the brass crescents of donkeys, horses, and other domestic animals are hung face downward, a position at once suited to the gait of the quadrupeds and identical with that of the crescents represented in statues of their divine protectress, Diana of the Ephesians. It follows naturally that the upright moon should be the one more frequently adopted on the cimaruta, and we find it to be so in most cases. The exceptions are generally when the crescent is represented in especial relation to some other emblem, such as the fist, which is then mounted between the horns of the crescent, like the familiar emblems on the face-plates of English cart-horses. It may be noted that, when in combination with the cimaruta, the loop for suspension of the crescent almost invariably survives as a small silver tag, which may or may not be perforated. The persistence of the loop is a clue to a very important fact concerning the origin of the combined charm, namely, that the crescent was at first a separate pendant amulet, probably of greater antiquity than the rue-sprig, and that it was hung with others on the rue-sprig like keys on a bunch.

An erroneous interpretation of this part of the charm has been given by Mr. Rolfe (Naples in 1888, p. II7), who has

In ornate specimens a perforated crown takes the place of the simple loop. 
been followed by Mr. Elworthy (Evil Eye, p. 345), in looking on the crescent moon as entwined by a serpent, one of whose coils forms the suspension-loop. Now, although I have carefully examined several cimarute of the type figured, including Mr. Rolfe's specimens, from which the drawing in question (PL. XII.) is believed to have been prepared, I have not been able to detect the serpent nor to convince myself of the existence of anything but the thickened rim of the moon-emblem and of its loop for suspension.

On first thoughts it would seem that the close association of antagonistic emblems (such as the moon and the serpent undoubtedly are), in one amulet, might detract from the power of the whole against evil, but that that view has not always been held is clear from the appearance of both serpent and lunar emblems in cimarute of a somewhat rare type, but even then they are not in close association.

In a particular series of charms (Figs. 12-15) we find that the lateral rue twigs have been curved and bent round so as to enclose the central portion of the charm in a manner that is very suggestive of the crescent emblem, and we are inclined to think that the silver-worker when executing these amulets was influenced by the idea of the horned moon being an essential part of the cimaruta.

Archrological evidence, I imagine, would show that the clenched fist and the crescent are the oldest of all the cimaruta emblems, and that the downcast form of crescent is more ancient than the upright form.

$$
\text { 4. } K e y \text {. }
$$

In most cimarute a key is placed near the moon. This emblem, like the crescent, can boast a considerable antiquity, for it was used as an amulet by the Etruscans, witness the finger-rings with tiny key-charms in the Bologna Museum (Elworthy). 
Plate XII.

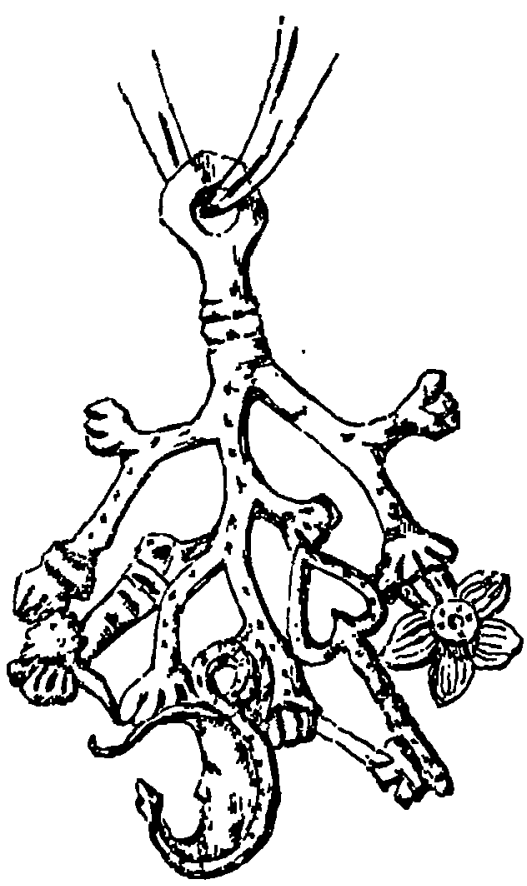

CIMARUTA No. 238.

(From Rotre, Naples in 1888.)

The rim and loop of supension of the moon have been erroneously represented as a serpent, and the cordate ahape of the handle of the key is ton pronounced. More accurate drawinge of the Cimarute of similar type are hown on Plate XVI.

To face p. 142. 
Plate XII.

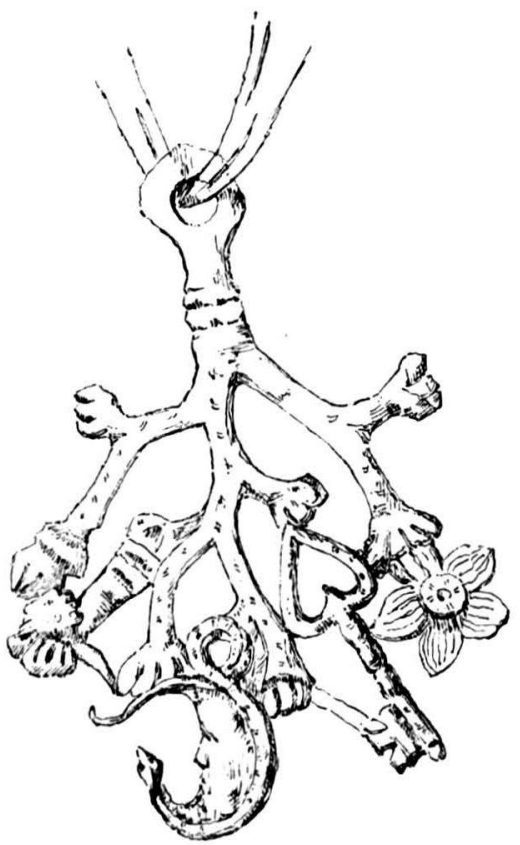

CIMARUTA No. 23в.

(From Rot.fF, Naples in 1888. )

The rim and loop of suspension of the moon have been erroneously represented as a serpent, and the cordate shape of the handle of the key is too pronounced. More accurate drawings of the Cimarute of similar type are shown on Plate XVI. 
The key of the cimaruta is now of the modern type. Its form seems to have been derived from that of the beautiful and ornate keys of the cinquecento. When keys are worn as simple amulets the bows are more elaborately worked than those of the keys in the cimarute; they may be wrought to the design of scrollwork, or be drilled with one, three, or four perforations; and in especially ornate examples I have seen the two-headed eagle (PL XIV.). Crossed keys, evidently suggested by the keys of St. Peter, are occasionally worn as a charm. When in combination with the cimaruta, the bow of the key is generally trefoilshaped, but I cannot accept Mr. Elworthy's theory that the handle of the key was intended to symbolize a heart. He may have been misled by an illustration (PL XII.) in which the artist has drawn this part more like a heart than the original warranted, for there is no more reason to think a heart was intended than that Diana Triformis was especially symbolized by the trilobed perforation of the bow. The shape is only the outcome of a striving after beauty of form.

Whether or not the key is a "conventionalized representation of the crux ansata" (Elworthy, p. 353), which was used as a charm in ancient Egypt and in modern Cyprus, I am unable to say; but there is no doubt that the key was the proper attribute of Jana, ${ }^{1}$ the form in which Diana opened and closed the gates of night, and thus finds an appropriate place with the rue ${ }^{2}$ and the crescent. $\mathrm{Mr}$. Rolfe has also drawn attention to the so-called key which was found in the hand of Isis, discovered at Pompeii ; but is it not possible that this may really have been a sistrum, or some other object, which was the real prototype of the "key" of the cimaruta?

2Mr. Elworthy points out that the Neapolitan word for witch is jarara.

In this connection it will be remembered that certain moon-plants, such as the Mloonwart Fern (Botryehimm Innaria), like the Mistietoe and the Artemisia, are, like the Schlidssel-blims (or Primrose), plante which have the power of opening locke. 


\section{Flower.}

The flowers which occur in cimarute fall into two groups: firstly, there are the flowers with few (four or five) petals, which recall the flowers of the rue (Figs, 19, 23); and, secondly, there are the flowers which have more numerous petals, which we shall term moon-flowers (Figs. 24, 27a).

The rue-flowers are sometimes represented as growing naturally at the ends of the twigs, and each is then formed from a separate sheet of silver, beaten into the shape of a bell and fixed to the twig (similarly the knobs in which the branches end may be considered as the flower buds or seed capsules of the rue), but often the workman by moulding the cimaruta from one piece of silver has displayed the flower flatly, so that it presents the appearance of having been clumsily stuck on by one petal (Plate XVI, Fig. 23D).

The flowers are sometimes independent of the sprig, and are then supported by one of the other constituents of the charm. A common example of this is the flower held in the clenched fist, a combination often to be met with as a separate amulet. This charm is seen in its greatest perfection in the silver spadini worn by Sorrentine women in their hair. The flowers have four petals. ${ }^{2}$ There is no absolute proof that these bodkin-flowers are related to the flowers on the cimaruta; there may be cruciferous flowers which resembled the periwinkle or violette des sorciers, in that they may once have been used in the manufacture of amulets. But, bearing in mind the fact that this particular type of charm is especially worn by women, a more probable explanation is that the flower is either beneficial to the fair sex or else is the emblem of something that

1 One specimen examined had evidently been slightly damaged, and $s^{0}$, apparently with the intention of concealing the injury, the silversmith had bent and engraved the four petals so that the mutilated one might form the head of a bird, the three undamaged petals forming the wings outstretched and the tail (Fig. 2. iii.). For a photograph of an entire spadino, see Italian Jewellery collected by Siguer Castallani, PL. 10, pablished by the Arundel Society, 1868. 
is. Now the orange-blossom plays so important a part in marriage customs, and at the same time is so closely related to the Rue (for both are of the same tribe Rutales) and is also so frequently found with four petals only, that I have no hesitation in associating the spadino flowers with the orange-blossom.

Sometimes flowers are carried by birds in their beaks, and are then more difficult to identify; and their presence as part of a charm against the evil eye is not easy of explanation, except in the belief of the ancients that birds are endowed with a marvellous knowledge of the medicinal properties of herbs. Hawks and eagles, to become farsighted, plucked hawkweed and wild lettuce respectively; pigeons and doves used vervain or pigeon's-grass, to counteract any dimness of sight which might prevent them from seeing their enemy, the hawk. So in these charms we may regard the flower as a contribution of the bird's to the general efficiency of the whole, or else as a private possession to increase his own power against the malign power of the evil eye.

The many-petalled flower is not common. In some cimarute in which I have found it, its stalk is pierced for suspension, and thereby we may recognize it as an amulet of originally independent existence. I believe that amulets of this type are intended to represent certain composite flowers, which perhaps, on account of their likeness to the full moon, were dedicated to Artemis or her equivalent. We are informed that the Moon Daisy (Chrysanthemum Leucanthernum), the flower of Eileithueia, or the Greek Juno Lucina, was used for uterine diseases. When the duties of the moon-goddess were transferred to St. Mary Magdalene and to St. Margaret of Cortona, the Moon-daisy became known as Maudelyn or Maudlinwort, just as the Marguerite Daisy, another flower of Artemis, was assigned to St. Margaret of Cortona. And there is some ground for putting into the same category Costmary or Maudlin 
(Balsamita vulgaris), the Maghet, Maids or May-weed (Pyrethrum parthenium), the Sweet Maudlin or Herba divae Marias (Achillea ageratum), the Mather or Mayd-weed (Anthemis cotula), and the Achillea matricaria-all of which plants, bearing flowers with white ray florets, were thought to resemble the moon, and to have acquired from her, by the doctrine of signatures, a certain efficacy in the treatment of feminine complaints.

Notwithstanding the differences in the cimaruta flowers Mr. Elworthy assumes that all indiscriminately "must be intended for the lotus, the symbol of Isis" (Evil Eye, p. 355). There seems but doubtful foundation for this assumption, as no such special virtues as those of the moon-flowers have been attributed to the lotus, ${ }^{1}$ which was the sacred emblem of the sun, the symbol of Osiris, and typified purification and regeneration?

And if, as I think, it is possible to explain the presence of these flowers as integral parts of the cimaruta, as being emblematic either of the healing powers of the rue itself, or of the virtues associated with other flowers sacred to the moon, it certainly does not appear necessary to adopt a theory which adds to the complexity and heterogeneity of the charm at the expense of simplicity and uniformity.

\section{Horn, Sword, Dagger, etc.}

In many cases a clenched fist may be seen grasping some object, not a flower, which is generally so indistinct that it has been variously explained as a horn, a sword, a dagger, or a fish, or as some other longish object, or taken merely as a bar of silver bridging the gap between two

1 The Egyptian Lotus is a Nymphoan.

An uncontrolled recognition of the lotus can sometimes proceed too far, as appears from Mr. Goodyear's Grammar of the Lotus (189I), in which there is a tendency to substitute that flower as the sole origin of all ancient decorations, including the Ionic volutes I 
emblems to strengthen the whole. No doubt the meaning of this charm would vary with the exact nature of the object held in the fist, but inasmuch as the execution of this part of the cimaruta is very defective, we can gain no satisfactory knowledge of what the prototypes may have been.

I have never been able to unhesitatingly recognize the fish in combination with the rue-sprig, although it is well known as a separate amulet. I cannot therefore include it in our list of symbols, for although Mr. Elworthy (Evil Eye, p. 355) mentions it, he does not give an illustration of it. Horns as amulets contro al fascino (Jorio) are of so great an antiquity and so widely distributed that it would be a matter for surprise that they have not been invariably added to strengthen the collection of cimaruta emblems, were it not that for a long period the elements in the combination were chosen simply for their efficacy in matters relating to childbirth, and that the moon-goddess in this capacity was sufficiently represented by the crescent.

\section{Cock.}

Occasionally in cimarute of elaborate design one or two birds are added to the other emblems; one is usually represented in profile and sometimes with a flower in its beak, the other is represented as seen from above and with wings expanded as if in full flight. The former bird is clearly distinguished as a cock by his comb, the latter has been identified as an eagle, but I would submit that it is intended for a cock volant. It is certainly not an owl (Figs, 22, 25^, 40).

Three separate theories may account for their presence. Both cock and eagle can be considered as able to overpower the evil eye by the power of their own eyes ; the one is noted for its extreme vigilance, the other for its piercing sight. The explanation which has been given of the flower in the beak 
of the cock ( $p, 145)$ is in accordance with this view. The second explanation would introduce a new idea into our conception of the cimaruta, viz, that these birds are the emblems of the sun-god, to whom both cock and eagle were held sacred, and that they thus contributed to the power of the charm to resist the evil eye. In Lycia both birds were sun-emblems, and were associated with the triscele. But the third idea harmonizes more aearly with the lunar associations of the charm. The cock, as Herr $E_{\text {. }}$ Baethgen has shown (De vi ac significatione Galli, 1887), was associated with Diana as well as with Proserpine, Esculapius, and other divinities-an association which is still preserved in two hair-pins I purchased in Fiume. In one, the cock is modelled in a sitting position above the head of a female figure, supposed to be Diana; in the other, the bird is represented with a crescent, a fist and a bunch of some herb. Occasionally the cock is represented by its head (Fig. 16) or merely by its comb (Figs. 17, 22), thus affording an excellent example of the gradual degeneration and disappearance of an amulet. The resemblance between the knuckles of a fist and a cock's comb is suggestive.

\section{Heart.}

The Heart, as one of the component emblems of the cimaruta, seems to me, all things considered, to be of late introduction. It is not certain that it was employed as an emblem by the Greeks or Romans when the cimaruta is believed to have had its beginning, it is not of frequent occurrence in the charms, it is not present in many of the most typical nor most elaborate; and where we come upon the heart-emblem most highly developed, there the rue is degenerate, and tends to be superseded by the newer element.

Let me repeat at the outset that the theory that the bow of the key was originally intended to represent a 
Plate XIII.

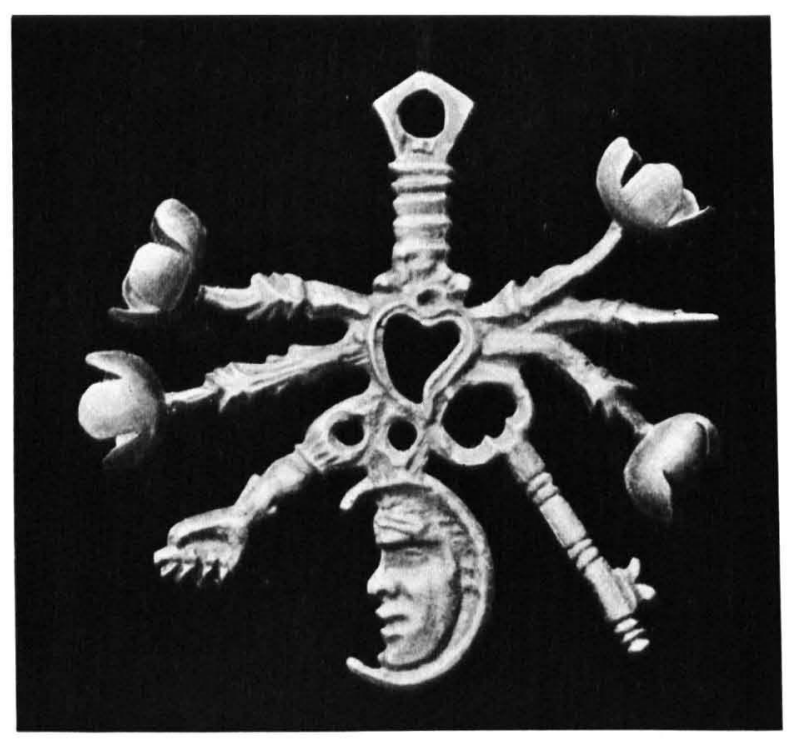

CIMARUTA.

A flower has fallen from the middle branch on the left, This specimen is described on p. 161 as No. 45.

To face p. 149 


\section{Its Structure and Development.}

heart cannot be accepted: such an interpretation of the emblem is an attempt to find by force as many different emblems as possible in the cimaruta.

In charms of various types, hearts do, however, make their appearance as distinct emblems. One or two hearts are to be seen suspended from a branch of the rue sprig (Fig. 27) or sometimes held by a fist grasping it by the large blood-vessels, which are sometimes very clearly modelled (Fig. 28).

In charms of another type (No. 45, Plate XIII.) we find the heart in the correct position anatomically, in the centre of the group of emblems which constitute the entire charm. The heart may form the centre of a degenerate rue sprig and in extreme cases (PL. XIII.) may entirely take its place, becoming the nucleus around which the other emblems are attached. In the latter case we find a tiny perforation or hole above the heart, which, like the hole in the tag above the moon, is a survival of an original loop for suspension.

In Naples hearts made of bone, coral, silver, gold, or other material are commonly worn as simple amulets. In their modelling the main blood-vessels are occasionally indicated; but more frequently by a curious alteration of the design the blood-vessels are represented as flames, such as those seen rising from the Sacred Heart venerated by Roman Catholics. But from the hearts in the cimaruta flames are never found issuing, blood-vessels not unfrequently.

\section{Serpent.}

The serpent emblem as an integral part of the cimaruta is of exceptional occurrence, perhaps for the reason already adduced; namely, that the moon is its bane, and that in consequence their presence side by side did not make for the potency of the charm. Still, when as in the very ornate specimen in the Empire style figured in Plate XVII., 
29, we find both moon and serpent combined in the same amulet, we can only assume that the work was executed by a generation of workmen ignorant of the antagonism between the separate emblems.

There have been many traditions woven around the serpent. In his Sanskrit names drig visha or drishti vasha ( $z$ "having poison in the eye") we have indications of his supposed power of killing at a glance, and in the Greek name ố $\phi$, of supernatural vision. These attributes would make him an argus-eyed antagonist, and one to deal death to the powers exercising fascination.

I am strongly of the opinion that there is a close relation between the inclusion of the emblem of the healing art among the cimaruta emblems and its presence in certain early illustrations of medicinal herbs. Several of the plants depicted in the Herbarium Apuleii Platonica, printed in Rome soon after 1480,1 are represented as being closely connected with serpents, scorpions, and other animals, which for the most part are the venomous animals against whose bites or stings the herbs were useful2 The serpent of the cimaruta may therefore in one sense be regarded as akin to a shop sign, like the red serpentine stripe on the barber's pole, meaning that the charm, like the barber, is efficacious even in the case of serpent-bite.

It is well known that Isis as the sign of her profession of a lady-doctor wore an asp crown, but, on the other hand, in an Egyptian wall painting, she is piercing the serpent through the head, reminding us of the original enmity between its seed and the woman.

I have not been able to trace any oriental or classical

\section{1]. F. Payne, On the Herbariws. (Traws. Bibliogr. Soc, Vi).}

A A similar tendency is exhibited in the coloured drawings of Verbena and the serpents in the 12th century Bodleian Herbal cited supra, p. 138, n 3 3 and also in many 15th century Italian MSS., of which Canon. Misc. 408 and 500 , and Bodl. MS. Add. A. 23 in the Bodleian Library, are examples.

'The survival of the serpent-entwined staff of Aesculapius. 
parallel to the Teutonic belief that household serpents or Unken are not only friendly to solitary children and drink milk with them, but that their lives are closely related to one another, so that if the snake be killed the child wastes away (Grimm and Simrock).

However, in view of the fact that the serpent appears to be of late introduction into the combined charm, I doubt whether it is worth discussing further as to whether its virtues are as good as the Ophites would have us believe, or its properties those of the basilisk.

\section{Corrucopia. II. Cherub.}

Other emblems appear in isolated cases, seemingly added in accordance with the fancy of maker or wearer or perhaps occasionally as erroneous interpretations of some obscure portion of the cimaruta from which the copy has been taken. Among such we find the cornucopia, indicative of plenty and good luck, and bupches of grapes (Elw. Fig. 8I), which probably have a similar meaning. The cimaruta shown in Fig. 28 has a cherub added to the other emblems. Their occurrence is so exceptional that I do not feel justified in accepting any explanation for their presence; for while they may on the one hand be regarded merely as elaborate birds, yet I feel certain that those who see Diana, the moon-goddess, in everything will compare them with the Egyptian winged Isis or with the bird-woman Hathor-and thus as being related to the Sirens.

\section{General Conclusions.}

In attempts to reconstruct the history of the cimaruta and to attribute due significance to its elements, it is but too easy to go wide of the truth by the adoption of one theory to the exclusion of all others. Many students will 
only give heed to the emblems of the sun-god or to those of Aesculapius, but it is the votaries of the moon-goddess who will perhaps find most in support of their presumption. Others, bent on finding relics of phallic worship, will so interpret more emblems than the occasion demands.

All my searches in museums for links between the cimaruta and the phallic amulets which were so common in Roman times, have led us to the conclusion that the cimaruta is not, as has sometimes been suggested, a descendant of any of them, but is essentially of separate origin. But, no doubt owing to the universality with which such amulets were worn, certain phallic elements were used at an early period to strengthen the rue charm, and they may have been inherited from the cult of Isis at Pompeii. In most cimarute the phallus is represented in the form of the hand or the horn.

Perhaps the charm had a material origin in an ancient practice of holding in the hand a sprig of rue culled from the plant, and later a dried sprig may have been attached by a mount to a chain or ribbon worn round the neck. Its efficacy is recorded by Aristotle, and the application of a herb at child-birth is quite in accordance with the old Persian lore concerning the seven fruits that charm away evil influence at parturition, and to which the fatal seven Hathors turn. The change from the materia medica itself to its symbolic representation in a more durable material is a very familiar one, and in the present case was possibly suggested by other arborescent amulets of quite another derivation, like the one engraved upon a green Assyrian cylinder now in the Hague Museum, and figured by Lajard in his Culte de Mithra (Plate 27, Fig. 7). The amulet, which is represented near a crescent moon, is like a three-branched spray of olive, and is to be interpreted as a local representation of the cosmic tree (PL. XI.).

The carliest cimarute, in short, may have been inspired by emblems of a tree-cult and have thus acquired other 
properties than those inherited from a medicinal herb, and may betoken the local acceptance of a world-wide myth, which some might perceive in the fable repeated by Pliny of the amicable relation between the fig (one form of the world-tree) and the rue.

Furthermore, the established practice of associating objects of various kinds with trees may suggestively account for the presence of the additional emblems on the cimaruta But it should not be assumed that the individual emblems of the cimarute have necessarily been associated with the world tree. Among these are the winged genii of the Assyrian Cosmic Tree, the eagle and hawk of the Scandinavian Ash, Yggdrasil, the eagle on the Iranian World-Tree, and the serpent.

From its erstwhile broader significance the rue as we have seen shrank to be the special protection of women in child-birth, and the emblems naturally added to it were those of the lunar goddess, the tutelary deity of maternity ; and the charm was made of her metal. The silver crescent and the moon-flower were no doubt soon followed by the key and by the cock, which, as Herr E. Baethgen has shown, was closely associated with Diana, an association which is still indicated by the two hair-pins purchased recently in Fiume, and referred to supra, p. 148.

There is no reason for believing the serpent to have been an original element in the compound charm, for although when worn by itself it might have been supposed to have intimidated the evil eye by its poisonous glance, or to have been a beneficial symbol, like the asp from the Isiac crown or the Aesculapian snake, yet the construction of cimarute seems to indicate that the traditional enmity put between the seed of the woman and the seed of the serpent had not been forgotten. And there are few more widely-spread beliefs than that in the toxic influence of the moon.

What cannot fail to impress the student in the investi- 
gation of this device, the cimaruta, is not so much the inclusion of this or the other emblem, as the general conformity to the type, and the almost entire absence from the combination, of amulets which we might have expected to find there. For instance, the horn, so universal in South Italy, is not common. Perhaps so pointed a weapon was too dangerous to be put into the hands of infants. The frog or toad emblem (Pl. XIV., o) we might also have expected to see included, for the frog-and-crescent charm, made of silver, is not unfrequently to be met with; and that it has been handed down from antiquity, bronze amulet-frogs found at Pompeii attest. Its absence may be explained by the fact that, as the frog had no connection with Diana Lucina, there was no reason for combining it with the cimaruta, and lack of original motive may unconsciously have been operative through the ages.

A similar explanation might be offered for the most remarkable fact of all, namely, for the almost entire absence of the Christian element from the cimaruta. The antagonism between amulets which have remained pagan and those which have been adopted as Christian has not yet been allayed. The only exceptions known to me are three in number, viz. a small cimaruta (Fig. 15), in which the cross appears, and two varieties of the crescent amulet, one of which has been inscribed JESUS MARIA, ${ }^{1}$ and the other, upon which some possessor has scratched a little figure of St. Januarius (P1. XIV.).

We have shown how the potency of the rue and of the emblems of the moon-goddess as amulets against the powers of evil was increased by emblems having no direct connection with her; prominent among these are those which are now universally considered insulting, but which doubtless had originally another meaning.

It is just this change in the exact significance of iden-

1 Elworthy, Evil Eye, Fig. 152. 
tical emblems and symbols which we find in different countries and in different times, that renders the study of charms at once so difficult and so fascinating. The crescentic face-plates on our dray-horses are now merely a smart ornament, the treasured belongings of the carters, who take a pride in keeping them brightly burnished, and transfer them from horse to horse; but in Southern Italy essentially similar pendant charms avert the Evil Eye, keep beasts from stumbling, and must be hanging on the animals when they are blessed by the priest on the day of St. Anthony (January 17th). Two thousand years previously the Campanian peasant would have seen in them the symbol of Diana, protectress of animals, earlier still the Egyptian would have perceived the emblem of Isis.

Lastly, let me remark that I am unaware of any reference to the cimaruta before 1888 . It may seem extraordinary that a charm so much worn in Naples should have escaped the attention of the earlier writers on Neapolitan manners and customs, but it must always be borne in mind that the wearers are nowadays, and probably always were, principally to be found among the lower classes, and, consequently, the unobservant of the upper class have either failed to notice it altogether or have considered it beneath their attention. Indeed, persons of some pretence to antiquarian reputation have denied the existence of these charms or have hinted that they are only roba Americana, made to be sold to tourists and curio-hunters.

It is to Mr. Neville Rolfe, the first to write on the matter, that I am much indebted, as the many references to his unique collection will show. Acknowledgements are also due to Mr. H. M. Bower, to my friend Mr. Whitnall, and to others who have allowed me to examine the amulets in their possession.

R. T. GüNTHER. 


\section{APPENDIX.}

Table of amulets connected with the Cimaruta. (See Plates XIV.-XVII.)

I have found it necessary to devise a simple method of representing the differences between individual cimarute. The following table will I hope be found helpful in the description not only of the charms at present under consideration but also of such other objects, like the mano pantea and the Barone lamps, which are composed of varying elements.

The composition of the cimaruta is represented by a constitutional formula in which the emblems are represented in order from left to right by their initial letters, and a series of brackets is employed to indicate mutual relationship of parts.

The following examples will make this clear.

Fig. 2 iii. (Plate XIV.) is represented as $H(F)$.

(A Hand holding a Flower.)

$\mathrm{R}_{\mathbf{2}}(\mathrm{H}-\mathrm{M}-\mathrm{H}-\mathrm{K}-\mathrm{H})$.

Rue sprig with 3 branches supporting in order from left to right a Hand-Moon-Hand-Key-Hand.

$R_{2}$ (H (F) K. bM Cock b Cock (F) b. b).

In this charm one Flower is held in a Hand and a second by a Cock. A second Cock is supported by the Moon. The two points divide the symbols into the three groups borne on the branches of the rue.

A dotted symbol, thus, $\dot{M}$, signifies that the loop for suspension is present.

\section{Elements of usual occurrence.}

\section{Simple Amulets.}

I. Rue. Symbol R.

2. Hand. $H$.

a. Mano cornuta.

b. Mano fica.

c. Mano pantea.

The hand is also occasionally found in other positions, but the mano fica position is the only one which occurs in cimarute. 
Plate XIV.

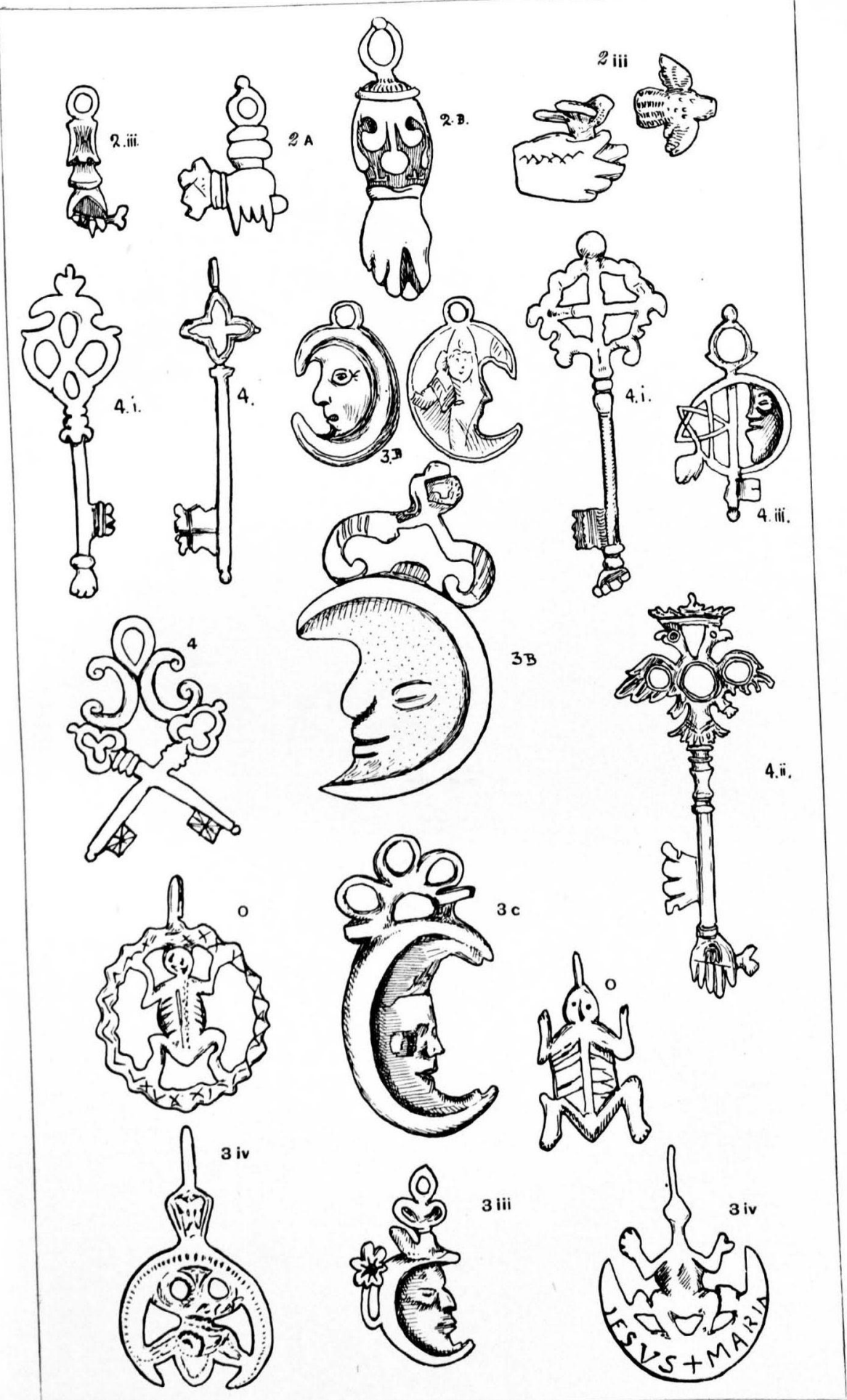

SIMPLE AND COMPOUND AMULETS.

To face p. 156 . 
3. Moon. M.
a. Downcast crescent.
b. Upright increscent. $\}$ Simple or Crowned.
a. Full.

4 Key. K.

a. Bow simple.

b. Bow ornate.

5. Flower. F.

a. Few-petalled Rue or Orange blossom.

b. Many-petalled Moon flower.

\section{Elements of rave occurrerce.}

6. Horn. +

Although common as a simple amulet the horn is rarely found in combination unless beld in a hand.

7. Cock (or Eagle ?)

a. Side view of entire bird.

b. Head.

c. Comb.

Elements belirved to be of comparatively late introduction.

8. Heart. C.

9. Snake.

10. Cornucopias, and occasionally appear: also the 11. Winged boys $\}$ Pentacle.

\section{COMPOUND AMULETS.}

2. i. $H(M)$ Hand holding moon

ii. $H(\mathrm{~K})$

" " key

iii. $H(F)$ " " flower

iv. $H(t)$ in a common donkey-charm.

horn or dagger.

Hairpin in authors' collection.

Elworthy, Fig. I12. Sorrentine bodkins and amulets.

the little finger

3. i. $\mathbf{M}(\mathrm{H})$ Moon enclosing hand.

ii. $M($ Cock $)$ " cock

Only known in

combination with the cimaruta. 
iii. M (F) Moon with flower. Rolfe Coll.

The moon amulet is not unfrequently united with the frog, PL. XIV. figs. 3. iv.

4 i. $K(H)$ Key ending in a hand.

Rolfe Coll

ii. $\mathbf{K}$ ( $\mathrm{H}(\mathrm{F})$ ) Key ending in a hand holding a flower.

iii. $K(M+P+H) K e y$ with moon, pentacle and hand.

8. i. C+Heart ending in a hom. A small iron charm. Author's Coll.

\section{Compound Amulets (Cimarute). \\ $A$ sprig of rue forms the basis of the asnulet.}

I. With a hand, but without moon and key together.

i. Simple forms.

10. R(bbb.H.b).

Author's Coll.

II. $\mathrm{R}$ (| bb. $\mathrm{H} \mathrm{H} b)$.

Author's Coll.

12. $\mathrm{R}$ (bb . H.b). Author's Coll.

13. $\mathrm{R}$ (bb |. H. bb).

Elw., Fig. 8I, Author's Coll.

I4. $R$ (b | . H.bb). True in I5 has been treated conventionally 15. Cross (M H). $\quad\left\{\begin{array}{l}\text { and has been transformed into a cross and } \\ \mathrm{a} \text { crescent. }\end{array}\right.$

i1. With the cock substituted for one of the rue-buds.

I6. R (b. Cock's head. H. b).

Rolfe Coll.

I7. $R$ (b. Cock's comb . H (F). b).

Rolfe Coll.

In this specimen the lateral buds are markedly tripartite, like the trisula in shape.

iii. With the moon.

18. $\mathrm{R}(\mathrm{b} \mid \cdot \mathrm{HM} \mathrm{M} \cdot \mathrm{bH} \mathrm{b})$.

Rolfe Coll.

iv. With the Key.

19. R(1F1blcl11 F.H(t).11lcK1F ), Rolfe and Author's Colls.

Design light, elegant and symmetrical, with numerous filiform leaves (1) which simulate small horns. The hand with the horn, the sole emblem on the middle branch, is situated almost exactly in the centre of an equilateral triangle, the angles of which are formed by the three 4-6-petalled flowers. Two heart-shaped leaves (CC) are borne laterally. 
Plate XV.

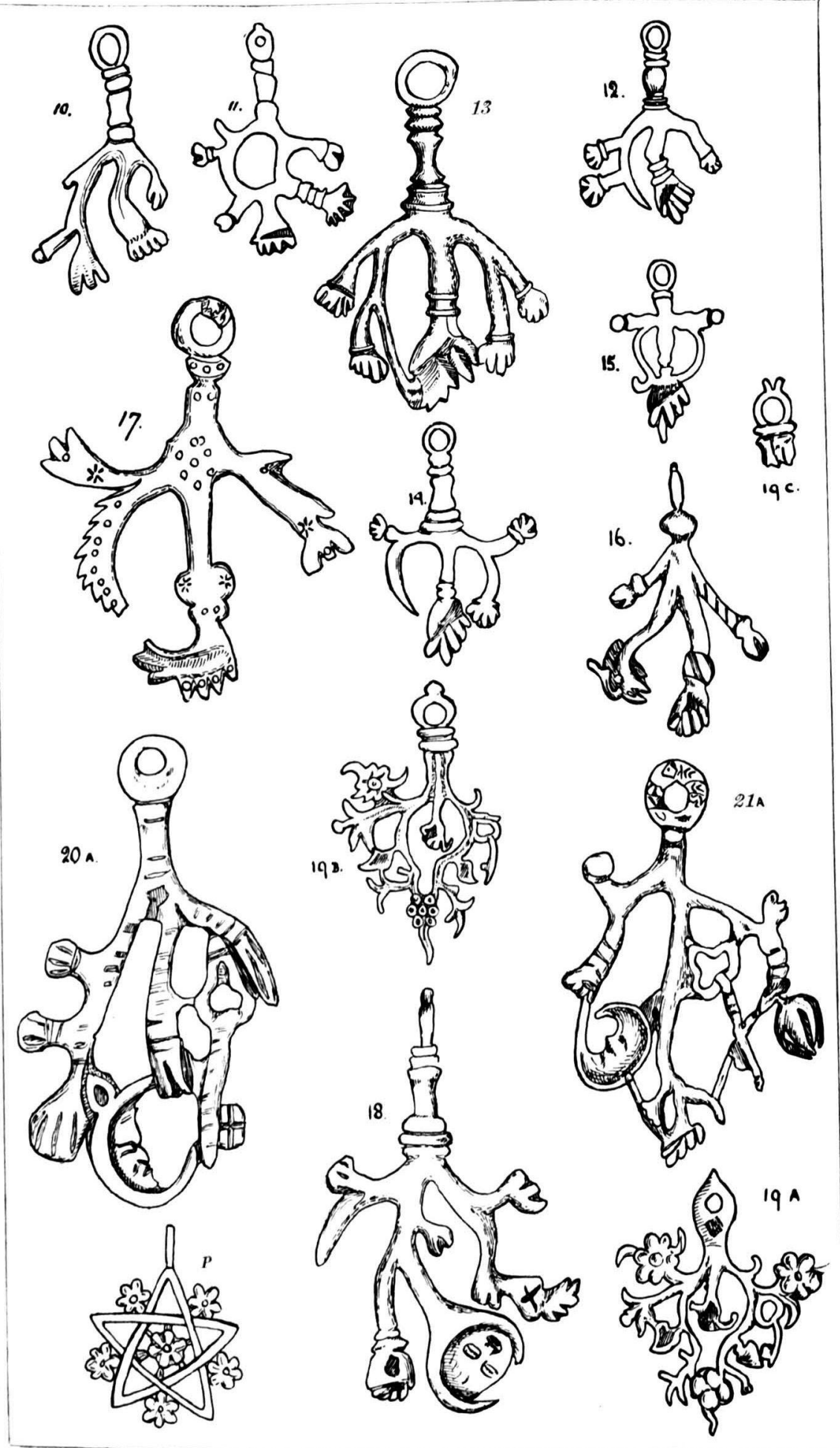



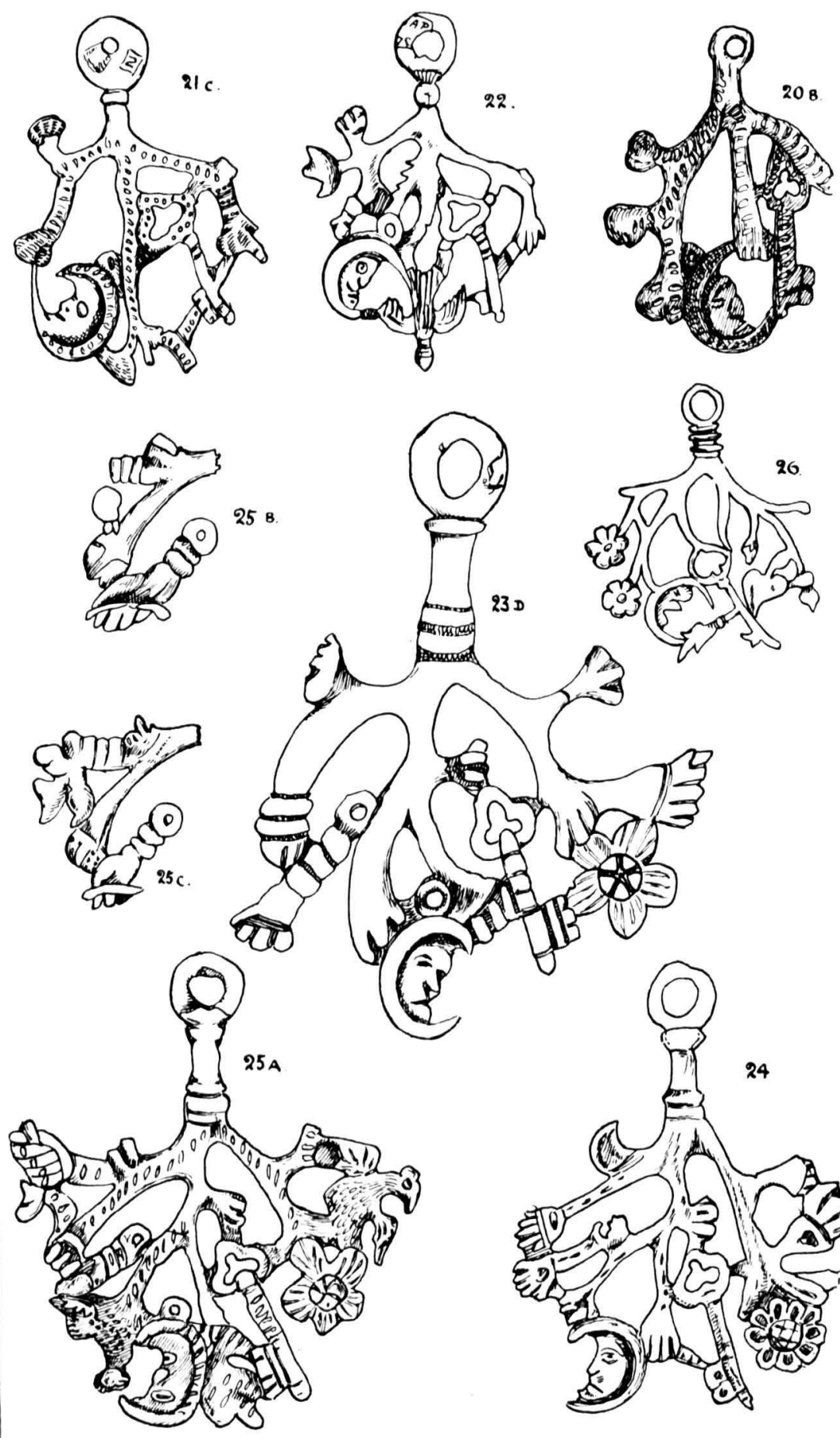
I believe this design to be of recent date. It is not uncommon.

Similar flowers (six petalled) are associated with the pentacle (PL XV. Fig. P.), Bower Coll, and with cimaruta No. 26.

II. Rue with three branches; moon and key present.

(a.) Typical Series.

Under this head are grouped the most typical cimarute. Other emblems may be added in varying combinations and positions, but generally they occupy the spaces between two branches and are often fixed by bars of silver.

20. $R$ (bbb $\dot{M} \cdot H \cdot \dot{K}$ b).

Rolfe Coll.

The hand does not reach the periphery of the charm and is but feebly differentiated from a bud Moon decrescent. In some specimens the buds are more phallic than in others. Hall mark $\mathbf{8}_{\mathbf{8}}^{\mathrm{N}}$.

21a. $\mathrm{R}(\mathrm{bb} \dot{\mathrm{M}} \cdot \mathrm{bH}+. \dot{\mathrm{K}} \mathrm{F} \mathrm{b})$.

Rolfe Coll.

Flower of sheet metal, soldered on. Moon increscent

2lb. $\mathrm{R}(\mathrm{bH} \dot{\mathrm{M}} \cdot \mathrm{bH}+. \dot{\mathrm{K}} \mathrm{H} \mathrm{b})$.

Author's Coll.

21c. $R(b b \dot{M} \cdot b H+. \dot{K} \quad b b)$.

Rolfe Coll.

Both of similar design to the last. The $\mathrm{bH}+$ at the end of the middle branch might easily become transformed into the moon enveloping the hand which appears in Nos. $3^{8}$ and 40.

22. $R$ (b F H Cock's comb $\dot{M}$. Cock. $\dot{K}$ bb)

Silver Mark ${ }_{78-}^{\text {NAP }}$ (date 1780-9). Author's Coll.

The saw-like structure is not easily identified as the comb of the cock, but there can be little doubt about it for it occupies the same relative position as the cock in Nos. 16, 17, 25.

23a. R(bb $\dot{H} . \mathrm{b} \dot{\mathrm{M}} \mathrm{b} \dot{\mathrm{K}} \mathrm{b} . \mathrm{b} \mathrm{F}$ b).

Whitnall Coll.

23b. R(bb $\dot{H} . \mathrm{b} \dot{M} \mathrm{~b} \dot{\mathrm{K}} \mathrm{b} . \mathrm{F}$ bb). Rolfe and Elw., Fig. $8 \mathrm{r}$. See PI. XII.

Whitnall Coll.

23c. $R(b b \dot{H} . b \dot{M} b \dot{K} b . b H b)$.

Author's Coll.

23d. $\mathrm{R}$ (bb $\dot{\mathrm{H}} . \mathrm{b} \dot{\mathrm{M}} \mathrm{b} \dot{\mathrm{K}} \mathrm{b} . \mathrm{bFHb})$.

Rolfe Coll.

24 R(bHH.bM b K b.F H b) Miss Wright.

The knuckles of the hands bear a strong resemblence to cocks' combs, Moon increscent. Flower a Moon-daisy.

- The cock might be interpreted as an Eagle by some anthorities. 
25a. R (b H (cc) b H (h) Cock. b $\dot{M}$ b C $\dot{K}$ b. b F Cock b). In this type we meet the cimaruta at the zenith of its development. The two cocks are clearly distinguished by their combs. The one to the left is represented as flying, the other as sitting. The heart (upside down) has, I believe, been derived from the hand and thumb in the corresponding position in No. 21.

Variations in the structure of the elements to the left of the charm are shown in 25 $\delta$ and 25c. Rolfe, and Author's Coll.

(b.) Series exhibiting variations from the type and a tendency towards the introduction of new emblems.

26. R(b F F M K. b C c b).

Bower Coll.

A charming and rare two-branched design.

27a. R(CC.K H.bM F).

27b. K(bC.KH(h)b.b M H).

Rolfe Coll.

28. R(b C.K F Winged boy.M H). Rolfe Coll.

29. $R(1 \mathrm{~K} \mathrm{M} \mathrm{m} \mathrm{H} \mathrm{K})$. Rolfe Coll.

The entire design has been remodelled in accordance with the conventions of the art of the Empire. The middle branch of the rue spray, has been represented as a serpent. One of the moons is represented as being nearly full. $m$ in the formula may represent a small crescent or a flower seen in side-view. The key on the right ends in a flower.

A less elaborate form is depicted by Elworthy, Fig. 81, but his photograph is indistinct.

30. $\mathrm{R}$ ( $1 \mathrm{~km} \mathrm{HMl}$ ).

3I. is a degenerate form which probably dates from the same period, but the details are almost impossible to unravel. A flower on a key-handle, a bunch of grapes, and a hand may perhaps be recognized. Elw., Fig. 8I, and Author's Coll.

(c.) Series showing degeneration as the result of spaces between the branches being left solid: disappearance of rue by hypertrophy.

32. $\mathrm{R}$ (b M H K b F).

Rolfe Coll.

33. $R(b M$ b Kb).

Rolfe Coll.

34. $\mathrm{R}$ (b M K F).

Author's Coll.

In this amulet the separate parts are almost quite unrecog. nizable.

(d.) Series exhibiting gradual disappearance of the rue by atrophy.

1. With Moon face downward.

35. R(H (F) K. b M (Cock) b Cock (F)b.b). 
(0)
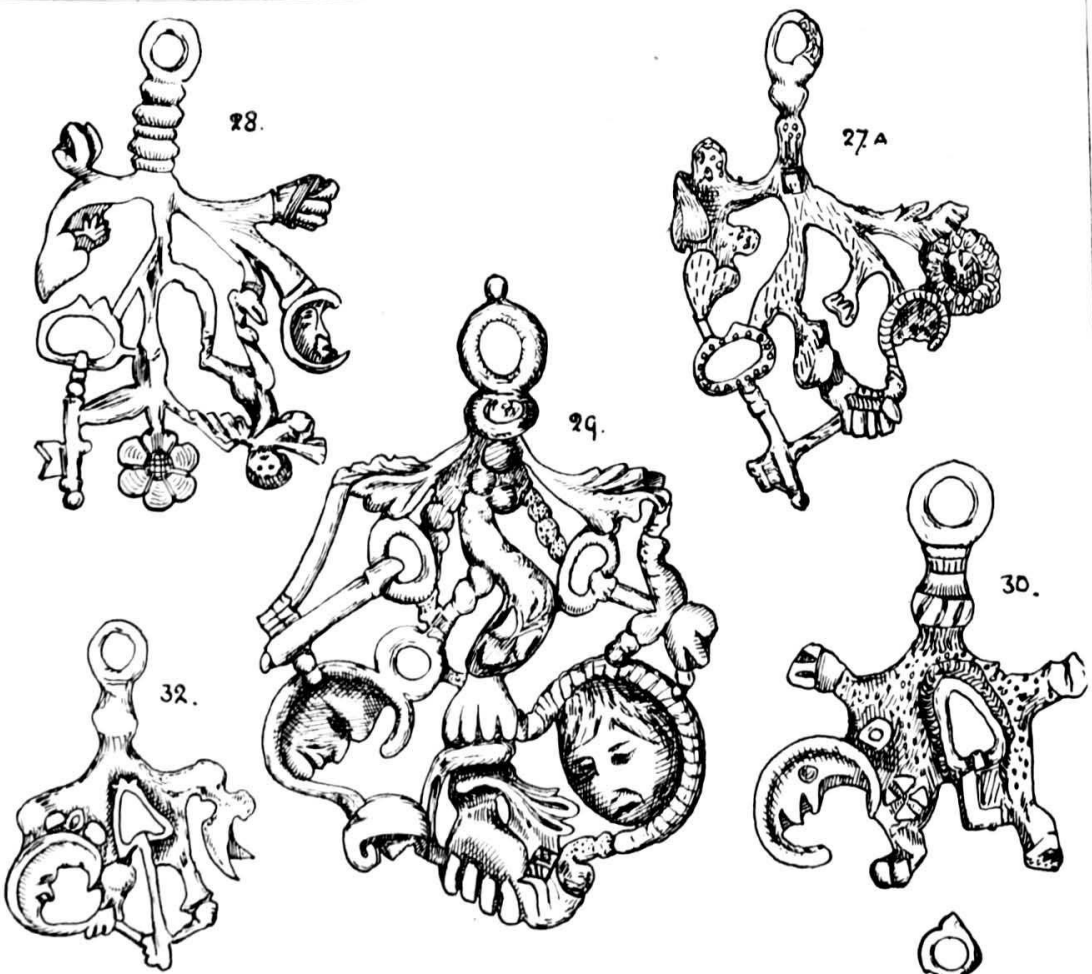
36. $R(H(F) K \cdot b M(\operatorname{Cock}) b \operatorname{Cock}(F) H(F) \cdot b)$.

37. $R(b M[H(F)] \cdot M[H(F)] \cdot \operatorname{Cock}(F) H(F))$.

Rolfe Coll.

Bower Coll.

A very unusual type of charm. The flowers are represented as held by four of the emblems and the combination of the crescent enclosing the hand bearing a flower occurs twice.

38. R(K.b M (H)b Cock (F) b. b). Rolfe Coll.

39. R(K.b M [H(F)] b F.b). Rolfe Coll.

40. $R(K \dot{M}(\mathrm{H}) \mathrm{F} \mathrm{H})$. Elw., Fig. 8I, and Author's Coll.

The rue-buds have entirely disappeared, and the typical branching is no longer recognizable.

ii. With moon upright, face forward.

The rue branching is not recognizable. The arrangement of the emblems tends to become either radial or gridiron-like.

41. (K M F H). a Moon decrescent.

Two forms of the flower have been noticed to occur in this amulet: (a) like those of Fig. 49, made of sheet silver. Rolfe Coll.

(b) cast in one piece with the amulet.

42. (F $\dot{H} \dot{M} \dot{K} F)$.

Author's Coll.

$\beta$ Moon increscent.

43. ( $\mathrm{F} \dot{\mathrm{H}} \mathrm{M} \mathrm{KF}$ ).

Author's Coll.

44. (F F H M F F F).

Mrs. Vernon.

45. C (F F $\dot{H} \dot{M} \dot{K}$ F F F).

Elworthy, Fig. 81.

In this fine example a heart has been cut in the centre of amulet, the other emblems being grouped radially around it. (PI. XIII.).

46. (H (F) K Cock M).

Author's Coll.

A common modern form, usually of poor workmanship, in which the various emblems are represented as banging by
separate bands or chains.

R. T. G. 